\title{
Seleção precoce de maracujazeiro pelo uso da correlação entre dados de produção mensal e anual
}

\author{
Leonardo Duarte Pimentel(1), Neusa Maria Colauto Stenzel(2), Cosme Damião Cruz(1) e Claudio Horst Bruckner ${ }^{(1)}$ \\ (1)Universidade Federal de Viçosa, Departamento de Fitotecnia, CEP 36570-000 Viçosa, MG. E-mail: agropimentel@yahoo.com.br, \\ cdcruz@ufv.br, bruckner@ufv.br ${ }^{(2)}$ Instituto Agronômico do Paraná, Caixa Postal 481, CEP 86047-902 Londrina, PR. E-mail: nstenzel@iapar.br
}

Resumo - O objetivo deste trabalho foi determinar épocas de avaliação da produtividade e de componentes da produção que permitam selecionar precocemente genótipos superiores de maracujazeiro. Foram avaliados 111 acessos de maracujazeiro amarelo, do Sul e Sudeste brasileiros, durante duas safras consecutivas. Avaliaram-se, mensalmente, as variáveis produção por planta, número de frutos por planta e peso médio de frutos. Os valores mensais e anuais dessas variáveis foram correlacionados à produção total acumulada em dois anos. Entre os dados mensais, os do terceiro mês tiveram a melhor correlação com os dados acumulados. Seleções positivas e negativas foram simuladas com os dados do terceiro mês e comparadas à seleção feita com base nos dados acumulados em dois anos. Os dados do terceiro mês da primeira safra foram adequados para a seleção quanto ao peso de frutos, mas as variáveis número de frutos e produtividade por planta seriam melhor selecionadas com os dados do terceiro mês da segunda safra.

Termos para indexação: Passiflora edulis, correlação fenotípica, produção acumulada.

\section{Early selection in passion fruit using correlation data between monthly and annual productivity}

\begin{abstract}
The objective of this work was to determine the sampling seasons of productivity and yield components, in passion fruit, that should allow early selection for superior genotypes. One hundred eleven genotypes of yellow passion fruit, from South and Southeast Brazil, were evaluated during two consecutive years. Variables were assessed monthly for: yield per plant, number of fruits per plant and average fruit weight. The monthly and annual data of these variables were correlated to total yield accumulated in the two years. Among the monthly data, the third month provided the best correlation with the accumulated data. Positive and negative selections were simulated with the third month data and compared with selection based on the two years accumulated data. The data from the third month of the first year were adequate for fruit weight selection, but number of fruits and yield per plant would be better selected with data from the third month of the second year.
\end{abstract}

Index terms: Passiflora edulis, phenotypic correlation, accumulated production.

\section{Introdução}

A cultura do maracujazeiro no Brasil apresenta produtividade média baixa, em razão de problemas fitossanitários, técnicas inadequadas de cultivo e baixa utilização de cultivares melhoradas. O reduzido número de cultivares e híbridos comerciais disponíveis dificulta o acesso do produtor a material propagativo de alta qualidade agronômica (Lima, 2005; Gonçalves et al., 2007). É de grande importância o aprimoramento dos trabalhos de melhoramento genético, nessa cultura, para acelerar o desenvolvimento de novas cultivares (Bruckner et al., 2002; Viana \& Gonçalves, 2005; Gonçalves et al., 2007).
Entre os vários métodos de melhoramento genético aplicáveis ao maracujazeiro, a seleção massal e a seleção massal com teste de progênie têm sido os mais utilizados. A seleção massal é eficiente para caracteres de fácil mensuração e com considerável herdabilidade ou em populações com alta variabilidade, como ocorre na maioria dos pomares de maracujá-amarelo (Bruckner et al., 2002).

$\mathrm{Na}$ cultura do maracujazeiro, a área ocupada por planta e a condução da planta sobre espaldeiras dificultam o processo de seleção. As plantas não permanecem individualizadas por muito tempo, pois os ramos das plantas vizinhas se misturam. Outro aspecto limitante para a seleção é o fato de o maracujazeiro 
florescer e frutificar por muitos meses e a produção ser baixa no primeiro, alta no segundo e decrescente no terceiro ano. Deste modo, a medição exata da produção por planta é um processo lento, trabalhoso e oneroso (Bruckner et al., 2002).

Na prática, os melhoristas avaliam a produção das plantas por dados amostrais, em períodos curtos, e estimam a produção total (Meletti et al., 2000; Viana et al., 2004; Negreiros et al., 2007). O maracujazeiro alterna períodos de grande frutificação com fluxos de crescimento vegetativo (Menzel \& Simpson, 1994), o que torna variável a taxa de frutificação ao longo do ano (Neves et al., 1999) e dificulta o estabelecimento de melhores épocas de amostragem, que possam representar com precisão a produção acumulada ao final do cultivo. A qualidade do fruto é influenciada pela época de colheita (Utsunomiya, 1992; Nascimento, 1999), o que evidencia a necessidade de se padronizar a metodologia de avaliação. Para simplificar e tornar mais ágil o processo de seleção, é necessário estudar épocas em que a avaliação da produção se correlacione melhor com a produção acumulada ao final do cultivo, para que se possa realizar a seleção precocemente, com boa representatividade.

O estudo de correlações nos programas de melhoramento genético é de grande importância quando se deseja fazer seleção simultânea ou indireta, principalmente quando o caráter de interesse apresenta problemas de medição (Cruz et al., 2004), como a produção do maracujazeiro. Essa estratégia permite ao melhorista simplificar o processo de seleção e obter progressos mais rápidos (Negreiros et al., 2007).

Maluf et al. (1989), ao realizar seleção em pomares comerciais, estimaram maiores ganhos genéticos quando a seleção foi feita com base nas avaliações de produção total e precoce (somatório das dez primeiras semanas) do que quando foi feita com base em caracteres de qualidade do fruto, como peso médio do fruto, teores de sólidos solúveis totais e percentagem de polpa. Esses dados indicam que, nas fases iniciais dos programas de melhoramento, em que se tem maior variabilidade genética na população, é mais importante identificar as plantas mais produtivas do que avaliar caracteres específicos do fruto, a fim de agilizar o processo de seleção.

É possível estabelecer estratégias de seleção baseadas na produção precoce, com a definição de épocas que permitam selecionar genótipos superiores com maior probabilidade de acerto, por meio de correlações lineares.

O objetivo deste trabalho foi determinar as épocas de avaliação da produtividade e de componentes da produção que permitam selecionar precocemente genótipos superiores de maracujazeiro.

\section{Material e Métodos}

Os dados foram coletados na Estação Experimental de Londrina, do Instituto Agronômico do Paraná, localizada a $585 \mathrm{~m}$ de altitude, $23^{\circ} 22^{\prime} \mathrm{S}$ e $51^{\circ} 10^{\prime} \mathrm{O}$. O clima local, segundo a classificação de Köppen, é do tipo Cfa com temperatura média anual de $21^{\circ} \mathrm{C}$. O solo da região é do tipo Nitossolo Vermelho distroférrico.

Foram avaliados 111 acessos de maracujá-amarelo (Passiflora edulis f. flavicarpa) quanto à produção, número de frutos por planta e peso médio de frutos. Os acessos avaliados originaram-se de regiões produtoras do Sul e Sudeste brasileiros (SC, PR, SP, MG e ES), e foram plantados no campo em setembro de 1998 , em espaçamento de $3,5 \times 6 \mathrm{~m}$ e conduzidos em espaldeira com um fio de arame. $\mathrm{O}$ experimento não foi irrigado, e a polinização foi natural.

As avaliações foram realizadas semanalmente ao longo de dois anos. No primeiro ciclo produtivo ("safrinha"), a produção estendeu-se por sete meses - de fevereiro a agosto de 1999. No segundo ciclo, o período de safra foi de oito meses: de dezembro de 1999 a julho de 2000. A colheita dos frutos foi realizada de uma a duas vezes por semana, de acordo a quantidade de frutos maduros. Foram quantificados os dados mensais de produção por planta (PP); número de frutos por planta $(\mathrm{NF})$ e peso médio de frutos (PMF).

Foram determinadas as correlações entre os dados dos dois anos - total acumulado ao final do ciclo produtivo - com os acumulados anuais e mensais, das três variáveis analisadas, a fim de verificar a época (mês) com maior representatividade do total acumulado nos dois anos. Para estimação do coeficiente de correlação, utilizou-se o programa GENES (Cruz, 2006).

Para verificar a possibilidade de se realizar a seleção precoce com bom percentual de acerto, ou seja, para verificar a acurácia do método proposto, foram simuladas seleções massais positivas e negativas. Foram usadas pressões de seleção de 10, 20, 30, 40 
e $50 \%$, correspondentes à seleção de $11,22,33$, 44 e 56 genótipos, entre os 111 acessos estudados, respectivamente. $\mathrm{O}$ percentual de acerto foi obtido a partir da comparação dos indivíduos que seriam selecionados com base nos dados relativos a cada mês e os selecionados com base nos dados acumulados em dois ciclos de produção (100\% de acerto). Os dados de cada acesso, em cada período estudado, foram ordenados em valores decrescentes (seleção positiva) ou crescentes (seleção negativa) e submetidos às pressões de seleção.

Em razão da importância de se realizar a seleção simultânea para vários caracteres, foi também estimada a correlação entre os totais anuais e os totais acumulados entre PP, NF e PMF.

\section{Resultados e Discussão}

Entre as três variáveis analisadas, observou-se maior correlação entre PP e NF, tanto em cada um dos anos considerados, quanto no acumulado em dois anos (Tabela 1). Resultados semelhantes foram encontrados por Martins et al. (2003), em maracujá-doce $(r=0,90)$, e por Negreiros (2006), que estudou ganhos indiretos na seleção combinada em maracujá-azedo $(\mathrm{r}=0,86)$. Esses resultados indicam que, quando se realiza a seleção para plantas prolíficas (maior NF), indiretamente ocorre a seleção para maior produtividade (PP).

Não foi observada associação significativa entre as variáveis PP e PMF (Tabela 1). Esses dados estão de acordo com os de Martins et al. (2003) e Negreiros (2006), que também não encontraram associação significativa entre esses caracteres. Por outro lado, entre NF e PMF houve correlação negativa, evidência de que,

Tabela 1. Coeficientes de correlação fenotípica entre três características, avaliadas em 111 acessos de maracujazeiro ${ }^{(1)}$.

\begin{tabular}{lcc}
\hline Variável & NF & PMF \\
\hline PP & $0,80^{* *}$ & $1^{-}$ciclo produtivo \\
NF & - & $0,03^{\mathrm{ns}}$ \\
\hline & & $-0,54^{* *}$ \\
PP & $0,74^{* *}$ & $2^{\underline{0}}$ ciclo produtivo \\
NF & - & $0,18^{\mathrm{ns}}$ \\
PP & \multicolumn{2}{c}{ Acumulado nos dois anos } \\
NF & $0,73^{* *}$ & $-0,51^{* *}$ \\
\hline
\end{tabular}

(1)PP, produção por planta; NF, número de frutos por planta; PMF, peso médio de frutos. ${ }^{\text {ns }}$ Não-significativo. $* \mathrm{e}{ }^{* *}$ Significativo a 5 e $1 \%$ de probabilidade, pelo teste $\mathrm{t}$. com o aumento do NF, pode haver progressiva redução no tamanho dos frutos. A correlação negativa entre NF e PMF é indício de que a excessiva quantidade de frutos pode levar à produção de frutos menores, com menor valor comercial, a exemplo do que ocorre com outros frutos (Scarpare Filho et al., 2000). Na literatura, os dados de correlação entre NF e PMF são divergentes. Viana (2001), Martins et al. (2003) e Negreiros (2006) não constataram associação significativa entre NF e PMF.

Provavelmente, PMF contribua para aumentar PP até certo patamar de NF, a partir do qual, a competição entre os frutos cause redução em seu peso. Os coeficientes de correlação de baixa magnitude indicam a possibilidade de selecionar plantas com frutos de bom tamanho e com maior número de frutos. $\mathrm{Na}$ seleção visando à produção para a indústria, a produtividade é mais importante do que o tamanho dos frutos. Na seleção visando o mercado de fruta fresca, o tamanho do fruto é de grande importância, em razão do maior valor de mercado alcançado por frutos grandes. $\mathrm{O}$ excesso de frutos, no entanto, pode ser evitado com menor intensidade de polinização manual, caso seja necessário.

Tanto no primeiro quanto no segundo ciclos da cultura, a PP e o NF apresentaram distribuição desuniforme ao longo dos meses (Figura 1). Nos dois anos, porém, tanto PP quanto NF foram ascendentes do primeiro ao terceiro mês. A oscilação na frutificação, ao longo do período produtivo, também foi observada por Melo et al. (2001). O período produtivo no maracujazeiro inicia-se com o fim do período juvenil, e o florescimento depende de dias longos (Watson \& Bowers, 1965; Menzel \& Simpson, 1988). Com dias longos, elevadas temperaturas e disponibilidade de água, a planta responde com intensa floração e subseqüente frutificação (Manica et al., 1985; Meinke \& Karnatz, 1990; Cavichioli et al., 2006). Entretanto, a competição interna por fotoassimilados, entre drenos resultantes da frutificação e do crescimento vegetativo, pode afetar o crescimento de novos ramos, necessários para novo florescimento. Após a queda ou colheita dos frutos, a planta lança novos ramos, seguidos de florada, o que resulta em alternância de crescimento vegetativo e frutificação, durante os meses produtivos.

Ao se avaliar a correlação entre a PP mensal e a PP anual com a PP acumulada em dois anos, observaramse maiores valores entre o total acumulado nos dois anos e o total do segundo ano (Tabela 2). Ao se 
comparar os dados mensais de avaliação, verificase que o terceiro mês de produção, em ambos os ciclos, apresentou as maiores correlações com o acumulado em dois anos, evidência de que esse período apresenta potencial para ser utilizado em seleções precoces.

Quando foi avaliada a correlação entre o NF mensal e o NF acumulado, os maiores coeficientes foram observados no segundo mês do primeiro ano e no sétimo mês do segundo ano, mas esses valores foram próximos aos do terceiro mês do primeiro e do segundo ano (Tabela 2). Tendo em vista que o terceir o mês é mais representativo na predição da PP e que essas características apresentam relação linear direta, conforme constatado neste trabalho e por Ritzinger et al. (1987), Viana (2001), Martins
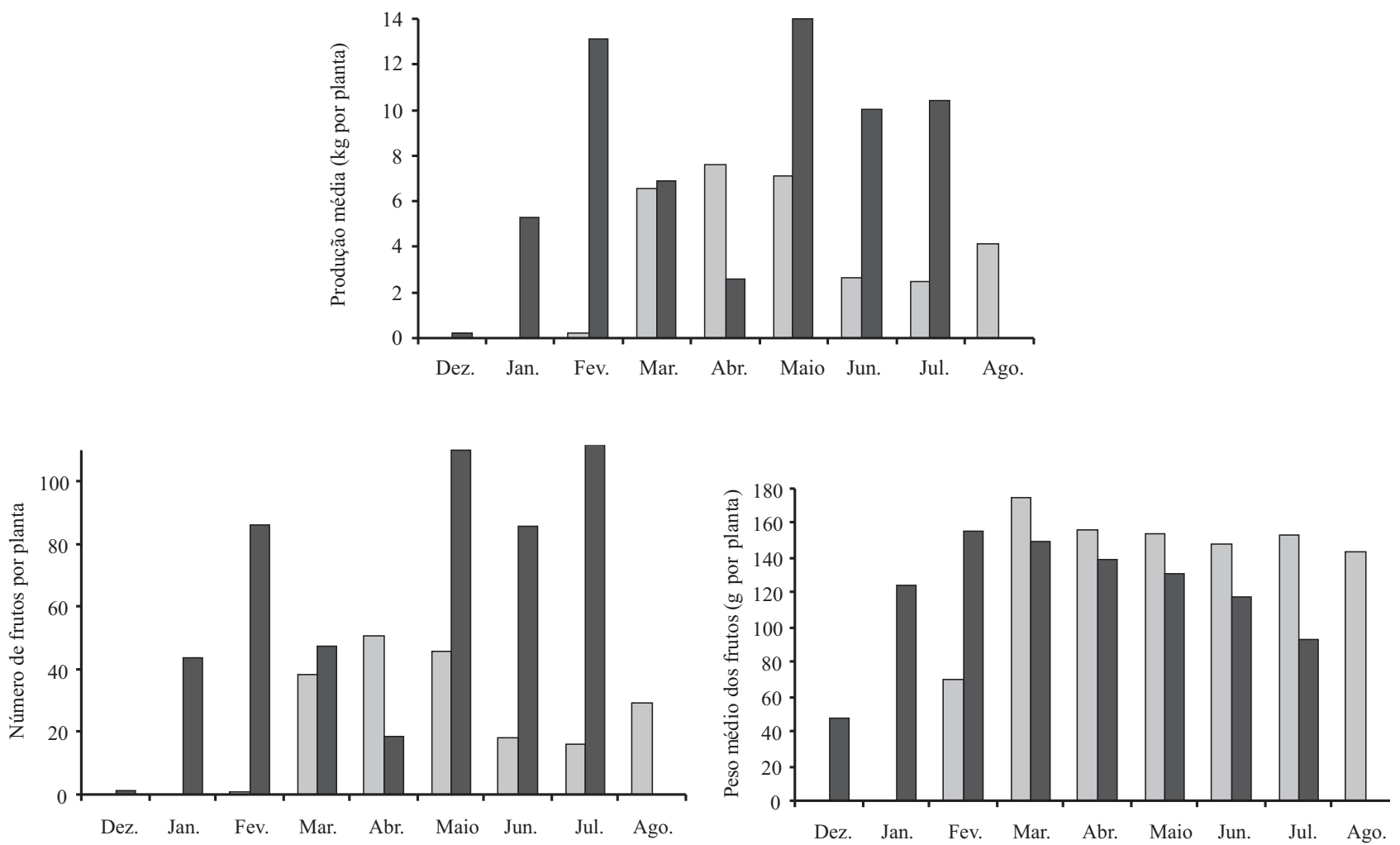

$\square 1^{\circ}$ ciclo $\square 2^{\circ}$ ciclo

Figura 1. Produção média mensal, número de frutos e peso médio de frutos, em 111 acessos de maracujazeiro.

Tabela 2. Coeficientes de correlação $\left(\mathrm{r}_{\mathrm{f}}\right)$ entre época de avaliação e produção por planta $(\mathrm{PP})$, número de frutos $(\mathrm{NF})$ e peso médio de frutos (PMF), no primeiro e segundo ciclo de produção de 111 acessos de maracujazeiro.

\begin{tabular}{|c|c|c|c|c|c|c|}
\hline \multirow[t]{2}{*}{ Época de avaliação } & \multicolumn{2}{|c|}{ Produção por planta } & \multicolumn{2}{|c|}{ Número de frutos } & \multicolumn{2}{|c|}{ Peso médio de frutos } \\
\hline & $1^{\mathrm{o}}$ ciclo & $2^{-}$ciclo & $1^{\mathrm{o}}$ ciclo & $2^{-}$ciclo & $1^{\mathrm{o}}$ ciclo & $2^{\underline{0}}$ ciclo \\
\hline $1^{\circ}$ mês $\mathrm{x}$ acumulado & $0,18^{\mathrm{ns}}$ & $0,35 * *$ & $0,28 * *$ & $0,35 * *$ & $-0,19^{*}$ & $0,07^{\mathrm{ns}}$ \\
\hline $2^{\circ}$ mês $x$ acumulado & $0,41 * *$ & $0,47 * *$ & $0,58 * *$ & $0,56^{* *}$ & $0,25 * *$ & $0,66 * *$ \\
\hline $3^{0}$ mês $x$ acumulado & $0,44 * *$ & $0,73 * *$ & $0,56 * *$ & $0,65 * *$ & $0,71 * *$ & $0,85^{* *}$ \\
\hline $4^{\circ}$ mês $\times$ acumulado & $0,07^{\mathrm{ns}}$ & $0,34 * *$ & $0,05^{\mathrm{ns}}$ & $0,39 * *$ & $0,71 * *$ & $0,65 * *$ \\
\hline $5^{\circ}$ mês $x$ acumulado & $0,03^{\mathrm{ns}}$ & $0,32 * *$ & $0,26^{* *}$ & $0,26^{* *}$ & $0,66 * * \mathrm{~s}$ & $0,64 * *$ \\
\hline $6^{\circ}$ mês $x$ acumulado & $0,26 * *$ & $0,46 * *$ & $0,38 * *$ & $0,58 * *$ & $0,50 * *$ & $0,73 * *$ \\
\hline $7^{0}$ mês $\mathrm{x}$ acumulado & $0,18^{\mathrm{ns}}$ & $0,62 * *$ & $0,45 * *$ & $0,67 * *$ & $0,59 * *$ & $0,61 * *$ \\
\hline $8^{\circ}$ mês $\mathrm{x}$ acumulado & - (1) & $0,13^{\mathrm{ns}}$ & - & $0,44 * *$ & - & $0,55^{\mathrm{ns}}$ \\
\hline Total anual $\mathrm{x}$ acumulado & $0,63 * *$ & $0,92 * *$ & $0,79 * *$ & $0,96 * *$ & $0,84^{* *}$ & $0,97 * *$ \\
\hline Total do $1^{\underline{0}}$ ciclo $x$ total do $2^{\underline{0}}$ ciclo & $0,28 * *$ & $0,28 * *$ & $0,59 * *$ & $0,59 * *$ & $0,71 * *$ & $0,71 * *$ \\
\hline
\end{tabular}

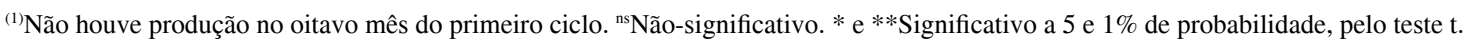


et al. (2003) e Negreiros (2006), pode-se considerar o terceiro mês como adequado também na avaliação do NF.

Os maiores valores de PMF foram observados no segundo mês do primeiro ciclo produtivo e no terceiro mês do segundo, a partir dos quais houve progressiva redução do PMF, particularmente no segundo ciclo (Figura 1). Ao contrário de PP e NF, que aumentaram, o PMF decresceu do primeiro para o segundo ciclo de produção, provavelmente em razão da maior competição entre os frutos por fotoassimilados, em decorrência do maior número de frutos por planta, conforme verificado em outras fruteiras (Scarpare Filho et al., 2000; Prado et al., 2007).

As maiores correlações entre o PMF acumulado e mensal ocorreram no terceiro e quarto mês do primeiro ciclo e no terceiro mês do segundo ciclo, o que evidencia que o terceiro mês, independentemente do ciclo, é representativo do PMF acumulado (Tabela 2). Entretanto, nessa característica houve menor variação ao longo dos meses e entre os anos de avaliação, com altas correlações em praticamente todo o período produtivo, exceto nos meses iniciais, que não foram representativos, em razão do reduzido número de frutos nas plantas, o que lhes proporcionou desenvolvimento além da média.

Na simulação da seleção baseada na PP, à medida que a pressão de seleção diminuiu, observou-se aumento gradativo no percentual de acerto (acurácia), em cada um dos dois ciclos avaliados (Figura 2). Foram observadas maiores percentagens de coincidência na seleção feita com base nos dados do segundo ciclo, o que está de acordo com os maiores coeficientes de correlação com o total acumulado observados nesse ciclo (Tabela 2). A seleção baseada no NF apresentou resposta similar ao da PP (Figura 2), porém com menor discrepância entre o primeiro e segundo ciclo.

$\mathrm{Na}$ seleção baseada no PMF, houve menor percentual de acerto na seleção positiva realizada com maior pressão de seleção, no primeiro ciclo (Figura 2). $\mathrm{Na}$ seleção negativa, assim como na positiva com pressão de seleção acima de $30 \%$, o percentual de acerto foi semelhante nos dois ciclos. Essa maior coincidência entre os genótipos selecionados a partir dos dois ciclos, observada para PMF, pode ser atribuída à menor oscilação dos valores dos coeficientes de correlação observados ao longo dos meses, para esse caráter, em relação aos demais (Tabela 2).

As plantas com baixos PMF podem ser descartadas já no primeiro ciclo, o que reduziria o trabalho com a
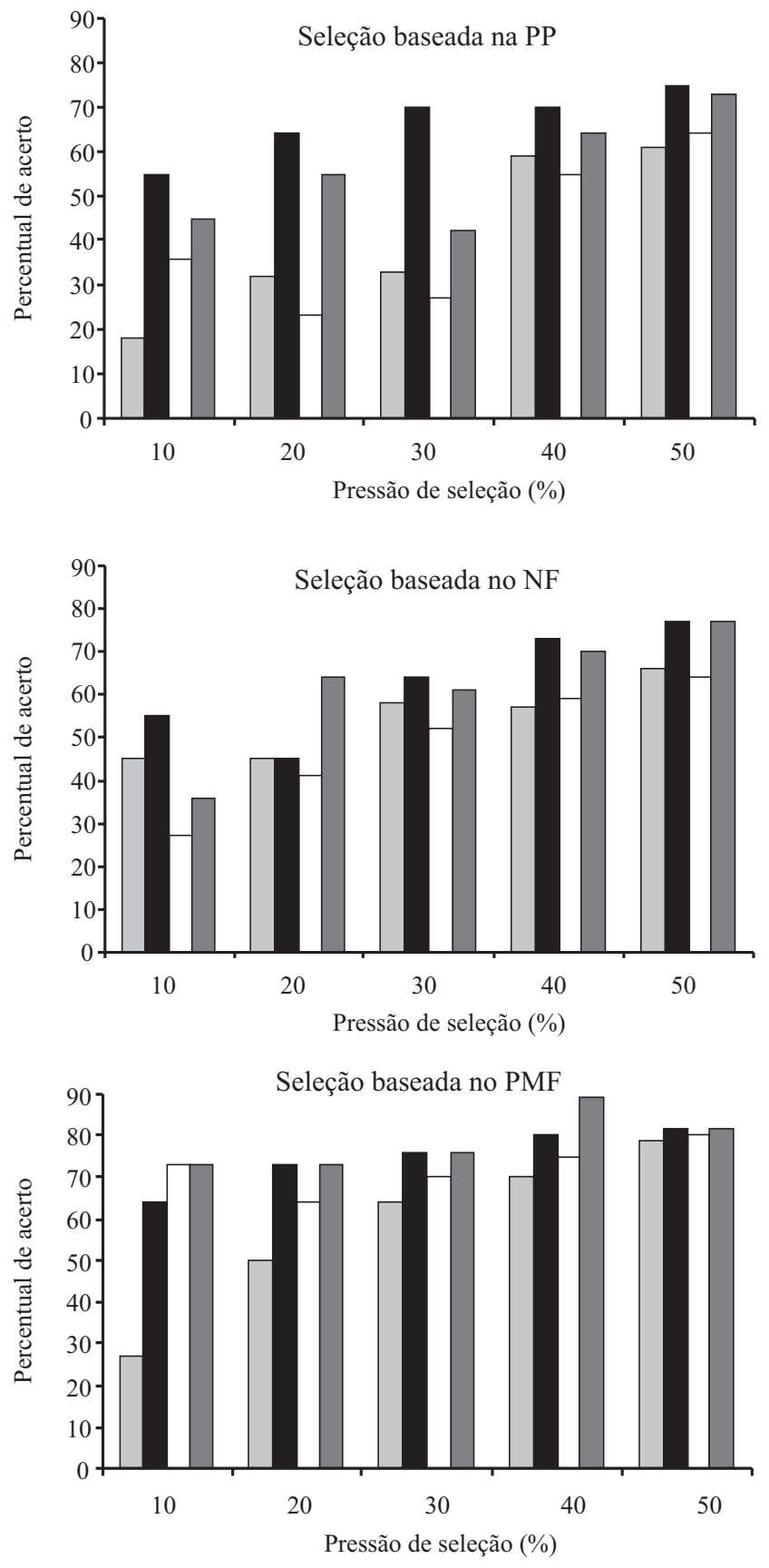

$\square$ Sel. positiva $1^{\circ}$ ciclo $\square$ Sel. positiva $2^{\underline{0}}$ ciclo $\square$ Sel. negativa $1^{\underline{0}}$ ciclo $\square$ Sel. negativa $2^{\underline{0}}$ ciclo

Figura 2. Percentual de acerto para seleção positiva e negativa, baseada na produção por planta (PP), número de frutos (NF) e peso médio de frutos (PMF), realizada com os dados do terceiro mês de produção, do primeiro e segundo ciclo, comparada com a seleção realizada com o resultado total - acumulado em dois ciclos -, de 111 acessos de maracujazeiro. 
seleção baseada em NF e PP no segundo ciclo, pela diminuição no número de plantas a serem avaliadas. Maluf et al. (1989) observaram correlação positiva $(\mathrm{r}=0,52)$ entre os dados de produção precoce (dez primeiras semanas) e a produção total do primeiro ano. Mesmo se feita no segundo ciclo, a seleção baseada no terceiro mês proporcionará significativa redução de custo, já que as avaliações não ocorrerão durante um período prolongado do ano.

\section{Conclusões}

1. O terceiro mês, dentro de cada ciclo produtivo, é representativo da produção, número de frutos e peso médio de frutos, acumulados em dois ciclos de produção do maracujazeiro.

2. O segundo ciclo produtivo é mais representativo da produção, número de frutos e peso médio dos frutos acumulados em dois anos.

3. A seleção de plantas com base no peso médio dos frutos no terceiro mês do primeiro ciclo produtivo, seguida da seleção baseada no número de frutos e produção no terceiro mês do segundo ciclo, pode simplificar e agilizar o processo de seleção em maracujazeiro.

\section{Agradecimentos}

Ao Conselho Nacional de Desenvolvimento Científico e Tecnológico, pelo apoio financeiro.

\section{Referências}

BRUCKNER, C.H.; MELETTI, L.M.M.; OTONI, W.C.; ZERBINI JÚNIOR, F.M. Maracujazeiro. In: BRUCKNER, C.H. (Ed.). Melhoramento de fruteiras tropicais. Viçosa: UFV, 2002. p.373-410.

CAVICHIOLI, J.C.; RUGGIERO, C.; VOLPE, C.A.; PAULO, E.M.; FAGUNDES, J.L.; KASAI, F.S. Florescimento e frutificação do maracujazeiro-amarelo submetido à iluminação artificial, irrigação e sombreamento. Revista Brasileira de Fruticultura, v.28, p.92-96, 2006

CRUZ, C.D. Programa GENES: estatística experimental e matrizes. Viçosa: UFV, 2006. 285p.

CRUZ, C.D.; REGAZZI, A.J.; CARNEIRO, P.C.S. Modelos biométricos aplicados ao melhoramento genético. Viçosa: UFV, 2004. v.1. 480p.

GONÇALVES, G.M.; VIANA, A.P.; BEZERRA NETO, F.V.; PEREIRA, M.G.; PEREIRA, T.N.S. Seleção e herdabilidade na predição de ganhos genéticos em maracujá-amarelo. Pesquisa Agropecuária Brasileira, v.42, p.193-198, 2007.
LIMA, A. de A. Aspectos fitotécnicos: desafios da pesquisa. In: FALEIRO, F.G.; JUNQUEIRA, N.T.V.; BRAGA, M.F. (Ed.). Maracujá: germoplasma e melhoramento genético. Planaltina: Embrapa Cerrados, 2005. p.643-677.

MALUF, W.R.; SILVA, J.R.; GRATTAPAGLIA, D.; TOMABRAGHINI, M.; CORTE, R.D.; MACHADO, M.A.; CALDAS, L.S. Genetic gains via clonal selection in passion fruit (Passiflora edulis Sims). Revista Brasileira de Genética, v.12, p.833-841, 1989.

MANICA, I.; RITZINGER, R.; KOLLER, O.C.; RIBOLDI, J.; RAMOS, R.M.; RODRIGUES, A.E.C. Efecto de seis espaciamientos de plantio sobre la producción del tercer año del maracuyá amarillo (Passiflora edulis f. favicarpa Deg.) em Viamão, Rio Grande do Sul, Brasil. Fruits, v.40, p.265-270, 1985.

MARTINS, M.R.; OLIVEIRA, J.C. de; DI MAURO, A.O.; SILVA, P.C. da. Avaliação de populações de maracujazeiro-doce (Passiflora alata curtis) obtidas de polinização aberta. Revista Brasileira de Fruticultura, v.25, p.111-114, 2003.

MEINKE, H.; KARNATZ, A. Influence of air and soil temperatures on grafted and self-rooted Passiflora hybrids. Scientia Horticulturae, v.43, p.237-246, 1990.

MELETTI, L.M.M.; SANTOS, R.R. dos; MINAMI, K. Melhoramento do maracujazeiro amarelo: obtenção do cultivar Composto IAC-27. Scientia Agricola, v.57, p.491-498, 2000.

MELO, K.T.; MANICA, I.; JUNQUEIRA, N.T.V. Produtividade de seis cultivares de maracujazeiro-azedo durante três anos em Vargem Bonita, DF. Pesquisa Agropecuária Brasileira, v.36, p.1117-1125, 2001.

MENZEL, C.M.; SIMPSON, D.R. Effect of continuous shading on growth, flowering and nutrient uptake of passion fruit. Scientia Horticulturae, v.35, p.77-88, 1988.

MENZEL, C.M.; SIMPSON, D.R. Passion fruit. In: SCHAFFER, B.; ANDERSEN, P.C. (Ed.). Handbook of environmental physiology of fruit crops. Boca Raton: CRC Press, 1994. v.2. p.225-241.

NASCIMENTO, T.B. do; RAMOS, J.D.; MENEZES, J.B. Características físicas do maracujá-amarelo produzido em diferentes épocas. Pesquisa Agropecuária Brasileira, v.34, p.2353-2358, 1999.

NEGREIROS, J.R. da S. Seleção combinada, massal e entre e dentro, análise de trilha e repetibilidade em progênies de meios-irmãos de maracujazeiro (Passiflora edulis f. flavicarpa). 2006. 128p. Tese (Doutorado) - Universidade Federal de Viçosa, Viçosa.

NEGREIROS, J.R. da S.; ÁLVARES, V. de S.; BRUCKNER, C.H.; MORGADO, M.A.D.; CRUZ, C.D. Relação entre características físicas e o rendimento de polpa de maracujá-amarelo. Revista Brasileira de Fruticultura, v.29, p.546-549, 2007.

NEVES, C.S.V.J.; CARVALHO, S.L.C.; NEVES, P.M.O.J. Porcentagem de frutificação, período de desenvolvimento dos frutos e unidades térmicas para maracujá-amarelo. Revista Brasileira de Fruticultura, v.21, p.128-130, 1999.

PRADO, A.K. de S.; MACHADO, E.C.; MEDINA, C.L.; MACHADO, D.F.S.P.; MAZZAFERA, P. Florescimento e 
frutificação em laranjeiras 'Valência' com diferentes cargas de frutos e submetidas ou não à irrigação. Bragantia, v.66, p.173-182, 2007.

RITZINGER, R.; MANICA, I.; RIBOLDI, J. Efeito do espaçamento de plantio sobre a produção do maracujá-amarelo em Viamão-RS. Pesquisa Agropecuária Brasileira, v.22, p.809-815, 1987.

SCARPARE FILHO, J.A.; MINAMI, K.; KLUGE, R.A. Intensidade de raleio de frutos em pessegueiros 'Flordaprince' conduzidos em pomar com alta densidade de plantio. Pesquisa Agropecuária Brasileira, v.35, p.1109-1113, 2000.

UTSUNOMIYA, N. Effect of temperature on shoot growth, flowering and fruit growth of purple passion fruit (Passiflora edulis Sims var. edulis). Scientia Hoticulturae, v.52, p.63-68, 1992.

VIANA, A.P. Correlações e parâmetros genéticos em populações de maracujazeiro amarelo (Passiflora edulis f. flavicarpa) e diversidade molecular no gênero Passiflora. 2001. 97p. Tese (Doutorado) - Universidade Estadual do Norte Fluminense, Campos dos Goytacazes.

VIANA, A.P.; GONÇALVES, G.M. Genética quantitativa aplicada ao melhoramento genético do maracujazeiro. In: FALEIRO, F.G.; JUNQUEIRA, N.T.V.; BRAGA, M.F. (Ed.). Maracujá: germoplasma e melhoramento genético. Planaltina: Embrapa Cerrados, p.243-274. 2005.

VIANA, A.P.; PEREIRA, T.N.S.; PEREIRA, M.G.; AMARAL JÚNIOR, A.T. do; SOUZA, M.M. de; MALDONADO, J.F.M. Parâmetros genéticos em populações de maracujazeiro-amarelo. Revista Ceres, v.51, p.545-555, 2004.

WATSON, D.P.; BOWERS, F.A.I. Long days produce flowers on passion fruit. Hawaii Farm Science, v.14, p.3-5, 1965.

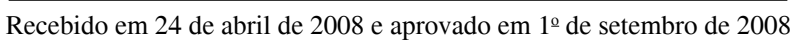

